\title{
Vowel Hiatus Resolution Processes as Delimiters of Prosodic Domains in Kisa
}

\author{
Emily Ayieta Ondondo \\ Department of Linguistics, Languages and Literature, School of Humanities and Social Sciences, Jaramogi Oginga Odinga University of \\ Science and Technology (JOOUST), Bondo, Kenya
}

Email address:

eondondo@gmail.com

\section{To cite this article:}

Emily Ayieta Ondondo. Vowel Hiatus Resolution Processes as Delimiters of Prosodic Domains in Kisa. International Journal of Language and Linguistics. Vol. 8, No. 4, 2020, pp. 164-173. doi: 10.11648/j.ij11.20200804.17

Received: July 6, 2020; Accepted: July 21, 2020; Published: August 10, 2020

\begin{abstract}
In a language, certain phenomena are sensitive to specific prosodic domains. In a model of morphology-syntax-phonology interaction in which morphological and syntactic structure projects phonological domains belonging to a set hierarchy, each phonological process refers to a specific level of that hierarchy. Therefore, describing a phonological process generally requires specifying the domain within which it applies. In Kisa, a Bantu language spoken in Western Kenya, a sequence of two vowels with different qualities is unacceptable. The ill-formed sequence is repaired through at least one of the vowel processes: gliding, coalescence, raising, assimilation and deletion. These vowel processes involve vowels occurring at different morphological and syntactic boundaries and apply within different prosodic domains in Kisa. Using a qualitative descriptive design and basing on data generated by the author as a native speaker of Kisa, this study identifies and describes the boundaries at which and the prosodic domains in which the vowel processes stated above apply. The findings show that unacceptable vowel sequences occur both at morphological and syntactic boundaries in Kisa. The strategies used to repair the unwanted vowel sequences at each boundary differ depending on the combining vowels. Further, the findings of the study show that the vowel processes attested in the language apply in different domains.
\end{abstract}

Keywords: Kisa, Vowel Hiatus Resolution, Prosodic Domain, Morphological-Syntactic Boundary, Gliding, Coalescence, Assimilation, Deletion

\section{Introduction}

In linguistic analysis, certain phenomena are sensitive to prosodic domains. In a model of morphology-syntax-phonology interaction in which syntactic structure projects phonological domains belonging to a set hierarchy, each phonological process refers to a specific level of that hierarchy [1-7]. Therefore, describing a phonological process generally requires specifying the domain within which it applies [1-9]. Kisa has five phonemic vowels given in (1). A sequence of two vowels with different qualities is unacceptable in Kisa, as in other Bantu languages [10-13]. The ill-formed sequence is repaired through at least one of the vowel processes: gliding, coalescence, raising, assimilation and deletion.

(1) i, e, a, o, u

The study of vowel sequences in the phonology of Bantu languages has been a subject of considerable theoretical discussion [10-11, 13-17]. There are cross-linguistic variations on when and how such sequences are separated in order to yield preferred patterns but the most common repair strategies are through epenthesis, glide formation, coalescence and deletion [10-17]. Different combinations of vowels behave differently in different environments and domains. Various patterns have been described that identify a range of special properties for high vowels in general and [i] in particular $[10-11,15]$. In an attempt to account for the special status accorded the high vowels in Yoruba, for instance, the patterns depend on a fundamental structural property, underspecification of the high front vowel [18]. While this account was successful for a certain range of data, subsequent work demonstrated the inadequacy of the underspecification hypothesis [19]. There has been no account, however, succeeding in integrating accounts of the diverse range of phenomena into a unified analysis [20]. Again, it is challenging to explain a situation where certain unwanted 
vowel sequences are tolerated in one domain but disallowed in another within the same language.

Vowel hiatus is a common phenomenon both within words and across word boundaries in Kisa as in other Bantu languages. There are also cases, in Kisa, where certain unwanted vowel sequences are tolerated in one domain but disallowed in yet another domain. This study, therefore, sets out to delimit the various prosodic domains in which the vowel processes that are used to resolve unwanted vowel sequences, in Kisa, apply. To do this, the study analyses possible combinations of the vowels in (1) at two major boundaries: morphological and syntactic and the vowel processes involved at each boundary. In this study, a morphological boundary is the boundary between an affix and a root, while a syntactic boundary is the boundary between a proclitic and a host as well as the boundary between two independent words, lexical and/or grammatical.

\section{Research Questions}

The study is based on the following questions.

What unwanted vowel sequences occur in Kisa?

At what boundaries do the vowel sequences occur?

What vowel processes are used to resolve the unwanted vowel sequences at each boundary?

In what prosodic domains do the vowel processes apply?

\section{Methodology}

The study used purposive sampling to select 1 female and 1 male informants based on their availability for data collection. Two informants were considered appropriate for the study given that every native speaker has the same linguistic competence about the language in question [21-23]. Although, working with one native speaker would yield the same results as working with more than one native speaker, and that consulting a range of speakers about the same phenomenon would lead to replications of information and eventually superfluous information [21-22], the use of two native speakers both male and female in this study was to help guard against representing the speech characteristics of one individual and gender.

Data in this study was collected through elicitation method using an elicitation frame as the instrument. An elicitation frame is a fixed environment that is used for discovering or testing particular linguistic phenomenon and its patterns in various appropriate paradigms [24]. Elicitation frames in this study were used to collect phonological patterns of vowel sequences at different boundaries in Kisa. Elicitation method was deemed appropriate for the study because the data required was concerned with the linguistic competence of the informants in the form in which it occurs. Given that the researcher and the informants have no control about such information, the most appropriate way to get it was to make the informants produce it involuntarily.

Data for the study was collected from the two informants using the elicitation frames. The informants were asked to articulate sequences of words with different vowel sequences and at different boundaries as was presented in the elicitation frames. The elicitation frames contained sequences of words with all possible vowel sequences at all possible boundaries in Kisa. Data analysis, on the other hand, involved organizing, describing, explaining and discussing the data collected according to the vowel sequences and processes that emerged and delineating the domains in which the vowel processes applied. The data analysed was presented in tables and descriptive write-ups in which examples alluded to were represented in a three or four tier format where appropriate and given morpheme by morpheme glossing.

\section{Findings}

The vowels outlined in (1) can combine at the boundary of different morphosyntactic structures in Kisa. This involves two major boundaries: a morphological and a syntactic boundary. The discussion that follows presents the vowel processes that come into play to resolve any unacceptable vowel sequences witnessed when vowels combine at each of these boundaries.

\subsection{Gliding}

Gliding, in Kisa, occur tautomorphemically and heteromorphemically. The high front vowel /i/ changes to the glide /y/ when followed by any of the other four vowels /e, a, o, $\mathrm{u} /$. Its mora is then compensated for by lengthening the following vowel. Consider the data in (2) and (3).

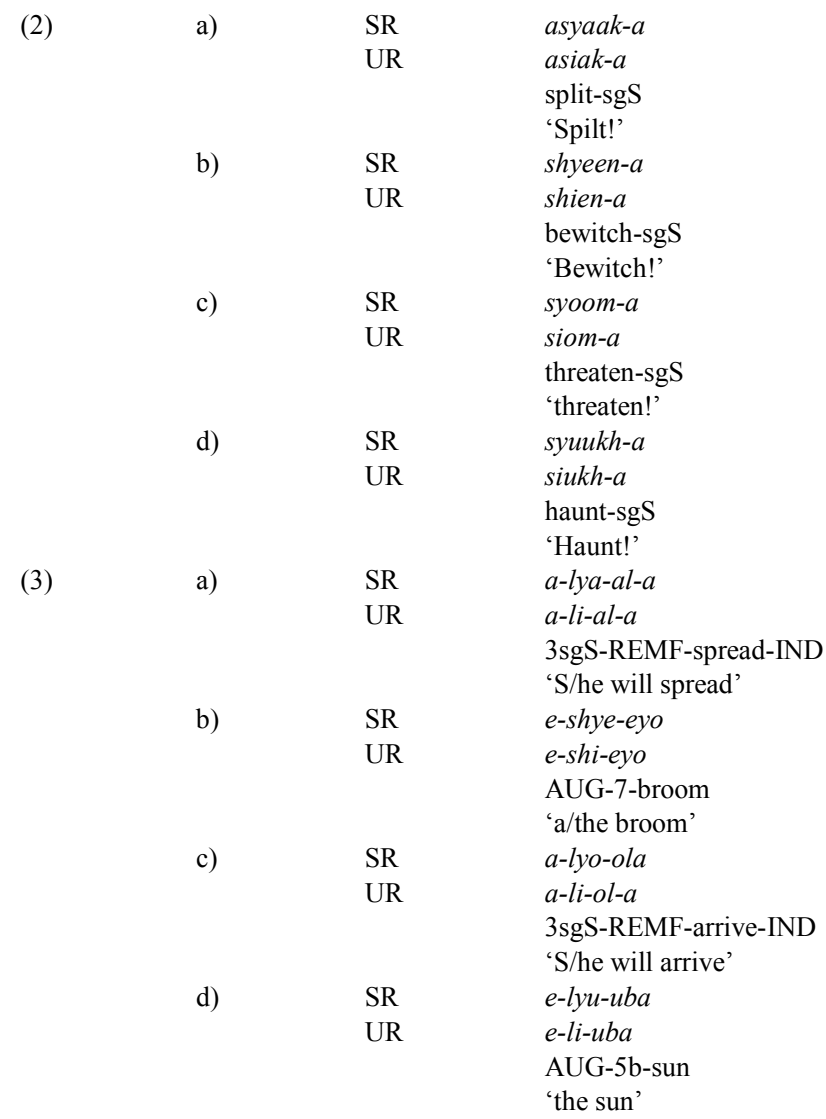


Similarly, the high back vowel / $\mathrm{u} /$ changes to the glide /w/ when followed by any of the other four vowels /i, e, a, o/, and its mora is as well compensated for by lengthening the following vowel as seen in the data in (4) and (5).

a)

b)

c)

d)

(5) d)

$$
\begin{aligned}
& \text { SR } \\
& \text { UR }
\end{aligned}
$$

$$
\text { SR }
$$$$
\text { UR }
$$$$
\text { SR }
$$$$
\text { UR }
$$

$$
\text { SR }
$$$$
\text { UR }
$$$$
\text { SR }
$$$$
\text { UR }
$$$$
\text { SR }
$$$$
\text { UR }
$$$$
\text { SR }
$$$$
\text { UR }
$$

$$
\text { SR }
$$$$
\text { UR }
$$

R

swaak-a
suak-a
pound-sgS
'Pound!'
mweeny-a
mueny-a
smile-sgS
'Smile!'
fwoon-a
fuon- $a$
beat-sgS
'Beat!'
kwiini
kuini
personal name
'Kwiini'
o-mwa-ana
o-mu-ana
AUG-1-child
'a/the child'
o-bwe-eni
o-bu-eni
AUG-14-forehead
'a/the forehead'
o-lwo-oba
o-lu-oba
AUG-11-mushroom
'a/the mushroom'
o-mwi-ika
o-mu-ika
AUG-3-year
'a/the year'

Note that it is only the high vowels /i/ and / $\mathrm{u} /$ that glide in Kisa.

\subsection{Coalescence}

Coalescence only takes place at a morphological boundary. When the low vowel /a/ is followed by the high front vowel /i/ at a morphological boundary, they coalesce to a long mid front vowel /ee/. Consider the data in (6).

$\begin{array}{lll}\text { (6) } & \text { SR } & \text { a-le-ets- } a \\ & \text { UR } & \text { a-la-its- } a \\ & & \text { 3sgS-HODF-IND } \\ & \text { 'S/he will come' } \\ & \text { SR } & \text { a-me-era } \\ & \text { a-ma-ira } \\ & \text { AUG-6-name } \\ & \text { 'the names' }\end{array}$

These examples show that when the low vowel /a/ is followed by the high front vowel /i/ at a morpheme boundary, the features [+low] from /a/ and [+high] from /i/ conflict. The non-conflicting features which survive are [-high] from /a/ and [-low, -round] from /i/ which are the features of the mid front vowel /ee/ that results.

Coalescence in Kisa also involves the combination of the low vowel /a/ and the high back vowel /u/ at a morphological boundary. These vowels coalesce to the long mid back vowel

/oo/, as the data in (7) shows.

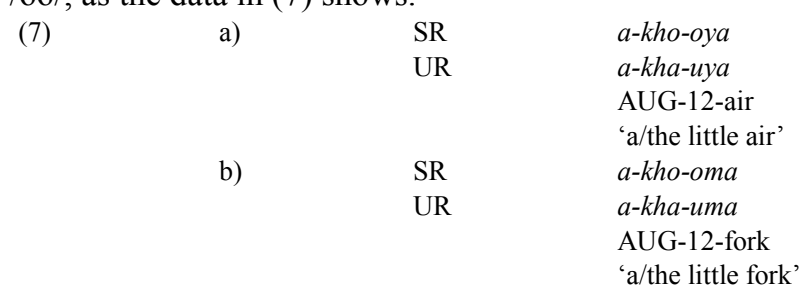

In this case, the features [+low] from /a/ and [+high] from $/ \mathrm{u} /$ also conflict. The non-conflicting features which survive are [-high] from /a/ and [-low, +round] from /u/ which are the features of the mid back vowel /oo/ that results.

These examples show that coalescence in Kisa involves the low vowel /a/ followed by the high front vowel /i/ or the high back vowel /u/. Therefore, cases of coalescence in Kisa are those involving two different vowels whose product is a single bimoraic one with non-conflicting features from the two vowels that combine.

\subsection{Raising}

We saw in the foregoing discussion that when the low vowel /a/ is followed by the high front vowel /i/ or the high back vowel $/ \mathrm{u} /$ at a morphological boundary coalescence takes place. When the same vowels combine at a syntactic boundary involving a proclitic and a host, raising takes place. The low vowel /a/ is raised to the mid front vowel /e/, before the high front vowel /i/. The data in (8) illustrates this.

$(8)$

$\begin{array}{cll}\text { a) } & \text { SR } & w-e=i-n-d a \\ & w-a=i-n-d a \\ & 1-\mathrm{AM}=\mathrm{AUG}-9 \mathrm{~b}-\text { stomach } \\ & \text { 'a/the glutton' } \\ & n e=i-n-d z u \\ \text { b) } & n a=i-n-d z u \\ & \text { with=AUG-9b-house } \\ & \text { 'with a house' }\end{array}$

There are no words in Kisa beginning with the high back vowel /u/.

The raising of the low vowel /a/ to the mid front vowel/e/ in the environment before /i/ harmonizes the crucial height difference between the combining vowels. So that the [+low] feature in /a/ that is in conflict with the [+high] feature in $/ \mathrm{i} /$ is lost when it is raised to the [-low, -high] vowel/e/, which lack either of the height features of the combining vowels.

Note, however, that the vowel that triggers raising does not change. The vowels /i/ preserves its [+high] feature. Consequently, after raising, a mid-vowel and a high vowel are concatenated. This implies that in Kisa when two vowels combine at a word boundary and the second vowel is a high vowel it preserves its [+high] feature. Raising, as the foregoing discussion shows only occurs at the boundary of a proclitic and a host. Furthermore, it involves the low vowel /a/ followed by the high vowel $/ \mathrm{i} /$.

\subsection{Assimilation}

In Kisa, assimilation takes place both at morphological and syntactic boundaries. When vowels combine at a 
morphological boundary, we saw in the preceding discussion that if the first vowel is either /i/ or / $\mathrm{u} /$ followed by any of the other vowels gliding takes place, and when the first vowel is $/ \mathrm{a} /$ and the second vowel is either $/ \mathrm{i} /$ or $/ \mathrm{u} /$ coalescence takes place. Nonetheless, when the first vowel is the low vowel /a/ and the second vowel is either /e/ or /o/, the first vowel /a/ assimilates completely to the second vowel, resulting into a long vowel, as shown in the examples in (9).

(9)

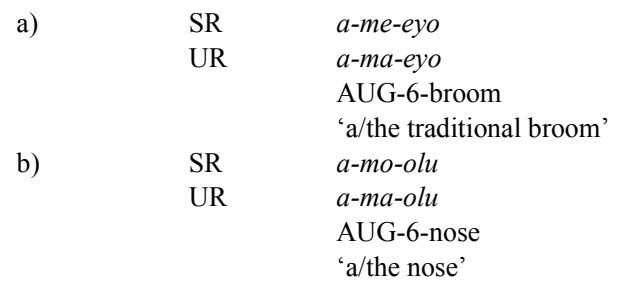

Assimilation also takes place at a proclitic-host boundary. When a proclitic ending with the vowel $/ \mathrm{i} /$ is combined with a host beginning with the vowels /e, a, o/, the vowel /i/ of the proclitic completely assimilates to the initial vowel of the host. Consider the examples in (10).

\begin{tabular}{|c|c|c|}
\hline \multirow[t]{3}{*}{ a) } & SR & she $=e n-d a-k u l-a=t a$. \\
\hline & UR & shi $=e n-l a-k u l-a=t a$ \\
\hline & & NEG=1sgS-buy-IND=no \\
\hline \multirow[t]{3}{*}{ b) } & SR & sha $=a-l a-k u l-a=t a$. \\
\hline & UR & $s h i=a-l a-k u l-a=t a$ \\
\hline & & $\mathrm{NEG}=3$ sgS-buy-IND=no \\
\hline \multirow{4}{*}{ c) } & & 'S/he will not buy.' \\
\hline & SR & sho $=0-l a-k u l-a=t a$. \\
\hline & UR & shi $=o-l a-k u l-a=t a$ \\
\hline & & $\begin{array}{l}\text { NEG=2sgS-buy-IND=no } \\
\text { 'You (sg.) will not buy.' }\end{array}$ \\
\hline
\end{tabular}

When a proclitic that ends with the vowel /a/ combines with a host beginning with the mid vowels /e/ and /o/, the low vowel /a/ of the proclitic completely assimilates to the initial
(14)
a)
SR
UR
a-bool-ere
a-bool-ere
$m b u=i-n$-gali
3 sgS-say/speak-HODP that=AUG-9b/c-big is-AUG-9b/c-good
' $\mathrm{S} /$ he said that the big one is good.'
b) $\quad \mathrm{SR}$
a-bool-ere
mbe $=$ en- $d a-k u l-a$.
a-bool-ere $\quad m b u=e n$-la-kul-a
3 sgS-say/speak-HODP that $=1$ sgS-buy-IND
'S/he said that I will buy.'
c) $\quad$ SR
a-bool-ere $\quad m b u=a-l a-k u l-a$
$3 \mathrm{sgS}$-say/speak-HOD that $=3$ sgS-buy-IND
'S/he said that s/he will buy.'
d) $\quad$ SR

$\begin{array}{lr}\text { a-bool-ere } & m b o=o-l a-k u l-a \\ \text { a-bool-ere } & m b u=o-l a-k u l-a \\ \text { 3sgS-say/speak-HODP that }=2 \text { sgS-buy-IND } & \\ \text { 'S/he said that you (sg.) will buy.' }\end{array}$

$$
\begin{aligned}
& \text { SR } \quad y a=a-l a-m u-b u k u l-a \\
& \text { UR } \quad y e=a-l a-m u-b u k u l-a \\
& 3 \mathrm{sg}=3 \mathrm{sgS}-\mathrm{HODF}-3 \mathrm{sgO} \text {-take-IND } \\
& \text { 'S/he will take him/her.' } \\
& \text { SR } \quad y o=o-l a-m u-b u k u l-a \\
& \text { UR } \quad y e=o-l a-m u-b u k u l-a \\
& 3 \mathrm{sg}=2 \text { sgS-HODF-3sgO-take-IND } \\
& \text { 'You (sg.) will take him/her.' }
\end{aligned}
$$

Similarly, when a proclitic ending with the vowel /o/ combines with a host beginning with the vowel /a/ and /e/ assimilation takes place, as seen in the examples in (13).

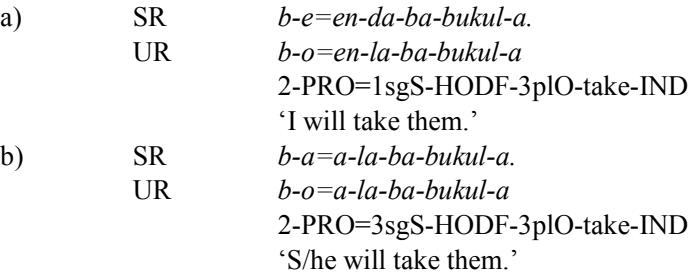

When a proclitic ending with the vowel $/ \mathrm{u} /$ is combined with a host beginning with the vowels /i, e, a, o/, the vowel /u/ of the proclitic completely assimilates to the initial vowel of the host. Consider the examples in (14).

When the first vowel is a mid-vowel, and the second vowel is the high front vowel / $\mathrm{i} /$, there is no assimilation. Consider the data in (15).

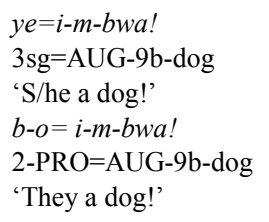


Assimilation also occurs at the boundary between two words. The following examples show that across word boundaries the first vowel assimilates totally to the following second vowel, as was the case with proclitic-host and root-affix combinations.

\begin{tabular}{|c|c|c|c|c|}
\hline \multirow[t]{10}{*}{ (16) } & a) & SR & e-mi-kache & $e$-my-aangu \\
\hline & & UR & e-mi-kachi & $e$-mi-angu \\
\hline & & & \multicolumn{2}{|c|}{$\begin{array}{l}\text { AUG-4-maize stalk AUG-4-light } \\
\text { 'light maize stalks' }\end{array}$} \\
\hline & \multirow[t]{4}{*}{ b) } & SR & $a-m a-a n a$ & $a-m a-a n j i$ \\
\hline & & UR & a-ma-ani & $a-m a-a n j i$ \\
\hline & & & \multirow{2}{*}{\multicolumn{2}{|c|}{$\begin{array}{l}\text { AUG-6-strength AUG-6-many } \\
\text { 'a lot of strength' }\end{array}$}} \\
\hline & & & & \\
\hline & \multirow[t]{3}{*}{ c) } & SR & o-mu-khaso & $o$-mw-aangu \\
\hline & & UR & $o-m u-k h a s i$ & o-mu-angu \\
\hline & & & \multicolumn{2}{|c|}{$\begin{array}{l}\text { AUG-1-woman AUG-1-light } \\
\text { 'a light woman' }\end{array}$} \\
\hline \multirow[t]{7}{*}{ (17) } & \multirow[t]{4}{*}{ a) } & SR & $a-m a-y e e m b c$ & $a$-me-engu \\
\hline & & UR & $a-m a-y e e m b e$ & $a$-ma-engu \\
\hline & & & \multirow{2}{*}{\multicolumn{2}{|c|}{$\begin{array}{l}\text { AUG-6-mango AUG-6-ripe } \\
\text { 'ripe mangoes' }\end{array}$}} \\
\hline & & & & \\
\hline & \multirow[t]{3}{*}{ b) } & SR & $o$-mu-reendo & $o-m w$-aangu \\
\hline & & UR & o-mu-reende & $o$-mu-angu \\
\hline & & & \multicolumn{2}{|c|}{$\begin{array}{l}\text { AUG-1-neighbour AUG-1-light } \\
\text { 'a light neighbour' }\end{array}$} \\
\hline \multirow[t]{7}{*}{ (18) } & \multirow[t]{4}{*}{ a) } & SR & e-mi-khaane & e-my-aangu \\
\hline & & UR & e-mi-khaana & e-mi-angu \\
\hline & & & \multirow{2}{*}{\multicolumn{2}{|c|}{$\begin{array}{l}\text { AUG-1-girl AUG-1-light } \\
\text { 'huge light girls' }\end{array}$}} \\
\hline & & & & \\
\hline & \multirow[t]{3}{*}{ b) } & SR & $o-m w$-aano & $o$-mw-aangu \\
\hline & & UR & o-mu-ana & o-mu-angu \\
\hline & & & \multicolumn{2}{|c|}{$\begin{array}{l}\text { AUG-1-child AUG-1-light } \\
\text { 'a light child' }\end{array}$} \\
\hline \multirow[t]{7}{*}{ (19) } & \multirow[t]{4}{*}{ a) } & SR & e-shi-kape & $e$-shy-aangu \\
\hline & & UR & e-shi-kapo & $e$-shi-angu \\
\hline & & & \multirow{2}{*}{\multicolumn{2}{|c|}{$\begin{array}{l}\text { AUG-7-basket AUG-7-light } \\
\text { 'a light basket' }\end{array}$}} \\
\hline & & & & \\
\hline & \multirow[t]{3}{*}{ b) } & SR & a-ma-teem- $a$ & $a-m a-a n j i$ \\
\hline & & UR & a-ma-teem-o & $a-m a-a n j i$ \\
\hline & & & \multicolumn{2}{|c|}{$\begin{array}{l}\text { AUG-6-try/tempt-NAG AUG-6-many } \\
\text { 'many trials/temptations' }\end{array}$} \\
\hline \multirow[t]{10}{*}{ (20) } & \multirow[t]{4}{*}{ a) } & SR & e-bi-tabe & $e$-by-aangu \\
\hline & & UR & $e-b i-t a b u$ & e-bi-angu \\
\hline & & & \multicolumn{2}{|c|}{ AUG-8-book AUG-8-light } \\
\hline & & & 'light books' & \\
\hline & \multirow[t]{3}{*}{ b) } & SR & a-ma-khuta & $a-m a-a n j i$ \\
\hline & & UR & $a-m a-k h u t u$ & $a-m a-a n j i$ \\
\hline & & & \multicolumn{2}{|c|}{$\begin{array}{l}\text { AUG-6-tortoise AUG-6-many } \\
\text { 'many tortoises' }\end{array}$} \\
\hline & c) & SR & $o-l u-f o$ & $o-l u$-unji \\
\hline & & UR & $o-l u-f u$ & $o-l u-u n j i$ \\
\hline & & & AUG-11-dus & iny \\
\hline
\end{tabular}

There is no assimilation whatsoever to a following [+high] [-back] vowel. Consider the following examples.

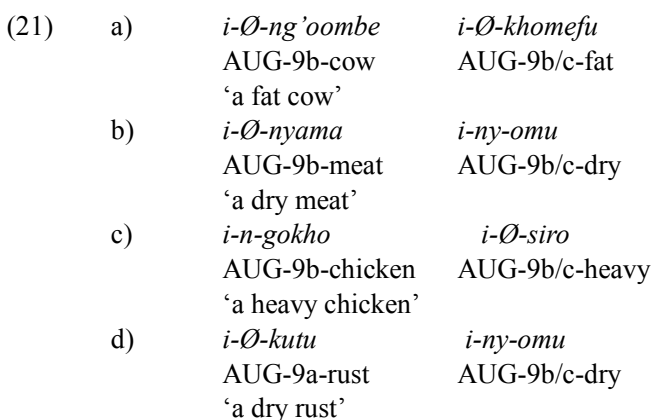

The preceding discussion shows that when two non-identical vowels come together at a morphological boundary, the first vowel assimilates to the second vowel only when the first vowel is /a/ and the second vowel is either /e/ or /o/. On the other hand, when two non-identical vowels combine at a proclitic-host boundary or at a boundary involving two words, the first vowel assimilates completely to the second vowel. Vowel assimilation at these boundaries in Kisa involves all the five vowels listed in (1), followed by the vowels /e/, /a/ or /o/ only. Vowel assimilation at the boundary between words only takes place when the second syllable of the following word has a long vowel. 


\subsection{Deletion}

Deletion takes place at a syntactic boundary involving two words. The final vowel of the first word is deleted whether the two vowels combining are identical or different. Consider the examples that follow.
(22)

a)

b)
SR
UR

SR

UR

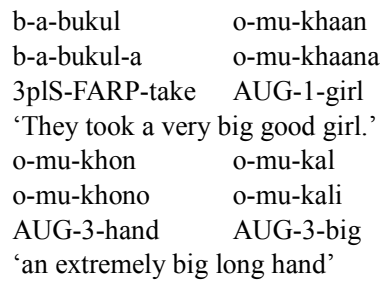

an extremely big long hand

Deletion does not take place when the following word begins with a high front vowel, as exemplified in (23) below.

$\begin{array}{lllcc}\text { SR } & \text { ba-la-bukul-a } & \text { i-Ø-kalaamu } & \text { i-Ø-siro } & \text { i-n-dayi } \\ \text { UR } & \text { ba-la-bukul-a } & \text { i-Ø-kalaamu } & \text { i- } \varnothing \text {-siro } & \text { i-n-layi } \\ & \text { 3plS-HODF-take-IND AUG-9a-pen AUG-9b/c-heavy AUG-9b/c-good } \\ & \text { 'They will take a good heavy pen.' }\end{array}$

Deletion, as the preceding discussion reveals, occurs at the juncture of two words. It takes place when any of the five vowels, in (1) is followed by the vowels /e/, /a/ or /o/ only. Additionally, it only takes place when the second syllable of the following word has a short vowel. If the second syllable of the following word has a long vowel, assimilation takes place as discussed in section 4.4 .

\section{Discussion}

Morphological and syntactic junctures have been topics of interest in phonological theory. One of the major issues addressed in the study of these junctures is how to predict from morphological and syntactic structure the domains of word-level and phrase-level rules of the phonology, or prosodic structure. Utterances are organized in a prosodic hierarchy, determined by but not isomorphic to syntactic structure [25-29]. From the discussion in the preceding section, it is clear that each of the vowel processes, discussed, occur at certain junctures and not others. This section examines the vowel processes discussed in the section above with the aim of determining the prosodic domains in which they apply.

\subsection{The Domain of Gliding}

In, Kisa as in other languages affixes and clitics cannot stand independently as phonological words. They must combine with their hosts to be realized phonologically. Therefore, complex and cliticised words in Kisa, like simple words, are natural candidates for being phonological words in this language.

Gliding takes place both in simple and complex words, in Kisa, as we saw in section 5.1. Given that simple and complex words are phonological words in Kisa as stated above, then it can be argued that the domain of gliding is the phonological word. Nevertheless, we saw in section 4.4 that when a proclitic ending in the high vowel /i/ is followed by a host beginning in any of the vowels /e, a, o/ gliding does not take place. Assimilation takes place instead. Given that a proclitic and a host also form a prosodic word, and gliding does not take place here when an appropriate trigger is present, then the domain of gliding needs the specification of the boundary at which it occurs. Therefore, gliding in Kisa, occurs within a phonological word either intramorphemically or at a morphological boundary.

\subsection{The Domain of Coalescence}

Vowel coalescence, as the discussion in section 4.2 shows, takes place only at the juncture between affixes and stems. As stated above, affixes and stems combine to form complex words and complex words are phonological words in Kisa. Given that coalescence takes place at the juncture between affixes and stems only, then it can be argued that the domain for coalescence is also the phonological word. However, since coalescence does not take place at the juncture between a proclitic and a host when an appropriate trigger is present as we saw in section 4.3, in which case vowel raising occurs instead, the boundary at which coalescence takes place needs to be specified as a morphological boundary within a phonological word.

\subsection{The Domain of Vowel Raising}

Vowel raising occurs at the juncture between a proclitic and a host only, as we saw in section 4.3. Morphologically and syntactically a clitic is an independent word. Hosts are also independent words, morphologically and syntactically. Consequently, vowel raising in Kisa occurs at a syntactic juncture because two syntactically separate words are involved. However, as stated above clitics and their hosts form single phonological words. Given that, vowel raising only takes place at a syntactic juncture involving a proclitic and a host and that a proclitic and a host form a single prosodic word, then I argue that raising takes place within a prosodic word but at a syntactic boundary.

It was noted in sections 4.2 and 4.3 that coalescence and raising are triggered by the high front vowel /i/ when preceded by the low vowel /a/. We have also seen above that the domain for coalescence and raising is the prosodic word but involves different boundaries. This then points to the fact that a sequence of the low vowel /a/ followed by the high front vowel /i/ across a morphological boundary within a phonological word is resolved by a different vowel process (coalescence) from the same sequence of vowels across a syntactic boundary (raising) within a phonological word. This, therefore, means that phonological processes help delimit the 
type of boundaries involved in given prosodic domains. So that coalescence occurs at a morphological boundary within a phonological word, while raising occurs at a syntactic boundary within a phonological word.

The crucial point, however, is that when the low vowel /a/ is followed by the high vowel, /i/ within a phonological word, they harmonise with each other as much as possible. In the case of coalescence, the resultant mid vowel /ee/ which is [-low, -high] does not have any of the crucial differences in the underlying vowels, that is [+low] for /a/ and [+ high] for $/ \mathrm{i} /$. On the other hand, the raising of the low vowel /a/ to the mid front vowel /e/, in the environment before, /i/, resulting into /ei/, harmonises the crucial difference between these two vowels, as described above. Note, however, that with vowel raising, the vowel that triggers raising does not change as opposed to coalescence. Since in the former a syntactic boundary is involved, while the later involves a morphological boundary, the feature [+high] is preserved at the beginning of a word and hence at syntactic boundaries, while it is not preserved at morphological boundaries.

After coalescence the two vowels result into a bimoraic vowel syllabified in the same syllable while after raising a mid-vowel and a high vowel are concatenated. Kisa, like other Bantu languages, has a syllable constraint which requires that a syllable have either a short vowel or a homorganic long vowel [30]. Consequently, the non-homorganic vowel sequence created after vowel raising, within a phonological word, sees each vowel syllabified in a separate syllable, demarcating clearly the syntactic boundary involved.

\subsection{The Domain of Assimilation}

We saw in section 5.4 that vowel assimilation occurs at the

$\begin{array}{ll}\text { a) } & \text { SR } \\ & \text { UR } \\ & \\ \text { b) } & \text { SR } \\ & \text { UR } \\ & \\ \text { c) } & \text { SR } \\ & \text { UR }\end{array}$

The preceding discussion shows that assimilation occurs within phonological words, across phonological words and across phonological phrase.

In view of the fact that the examples in (24) are made up of two phonological phrases, the domain in which assimilation takes place must be larger than the phonological phrase. In the

a)

b)
SR

UR

SR

UR juncture between affixes and stems. Since affixes and stems form phonological words, stated earlier, then vowel assimilation occurs within a phonological word. However, we also saw, in section 4.4, that vowel assimilation occurs at the juncture between proclitics and hosts. As argued earlier a proclitic and a host form a single phonological word. Therefore, the domain for vowel assimilation is still the phonological word.

Nevertheless, vowel assimilation does not only occur at the juncture of affixes and stems and proclitics and hosts alone. It also occurs at the juncture of two independent words, as we saw in section 4.4. The two independent words at this juncture are separate phonological words. This implies that assimilation at a word-word boundary does not occur within a phonological word but occurs in a different prosodic domain. This domain must, therefore, be larger than the phonological word. I argue that the domain in question is the phonological phrase following [1,4].

Phonological phrases must contain the syntactic head of the phrase. Modifiers to the left of the head must be incorporated into the phonological phrase containing that head, while modifiers to the right of the head cannot be so incorporated and have to form a phonological phrase of their own $[1,27$, 31-32]. Additionally, in right recursive languages, of which Kisa is, the phonological phrase includes the head and every element to the left of it. Whatever comes after the head is in a separate phonological phrase.

In the examples in (24), the first words constitute the heads of these syntactic phrases. The words that follow them are post modifiers of these heads. Therefore, each of the words in these examples constitutes a separate phonological phrase. As a result, there are two separate phonological phrases in these examples.

\begin{tabular}{|c|c|}
\hline$[e-m i-k a c h e]_{\mathrm{PP}}$ & {$[e-m y \text {-aangu }]_{\mathrm{PP}}$} \\
\hline e-mi-kachi & $e$-mi-angu \\
\hline AUG-4-maize stalk & AUG-4-light \\
\hline 'light maize stalks' & \\
\hline$[a-m a-a n a]_{\mathrm{PP}}$ & {$[a-m a-a n j i]_{\mathrm{PP}}$} \\
\hline a-ma-ani & $a-m a-a n j i$ \\
\hline $\begin{array}{l}\text { AUG-6-strength } \\
\text { 'a lot of strength' }\end{array}$ & AUG-6-many \\
\hline [o-mu-khaso] $]_{\mathrm{PP}}$ & {$[o-m w \text {-aangu }]_{\mathrm{PP}}$} \\
\hline o-mu-khasi & $o$-mu-angu \\
\hline AUG-1-woman, & AUG-1-light \\
\hline
\end{tabular}

literature [25-29] the prosodic level that is above that of the phonological phrase is the intonational phrase. Consequently, the constructions in (24) constitute intonational phrases, as shown in (25). Therefore, assimilation in these examples in Kisa, takes place within an intonational phrase.

\author{
$\left.[e-m y \text {-aangu }]_{\mathrm{PP}}\right)_{\mathrm{IP}}$ \\ e-mi-angu \\ AUG-4-light \\ $\left.[a-m a-a n j i]_{\mathrm{PP}}\right)_{\mathrm{IP}}$ \\ a-ma-anji
}




\begin{tabular}{|c|c|c|c|}
\hline & & AUG-6-strength & AUG-6-many \\
\hline ) & SR & $\begin{array}{l}\text { 'a lot of strength' } \\
\text { ([o-mu-khaso }]_{\mathrm{PP}}\end{array}$ & $\left.[o-m w \text {-aangu }]_{\mathrm{pp}}\right]_{\mathrm{IP}}$ \\
\hline & UR & $o-m u$-khasi & $o$-mu-angu \\
\hline & & AUG-1-woman & AUG-1-light \\
\hline & & 'a light woman' & \\
\hline
\end{tabular}

The example in (26) shows that if the first phrase is followed by two or more phrases, vowel assimilation will still apply across these phrases. This then implies that vowel assimilation will apply whether there is one phonological phrase or several phonological phrases in the construction.

$\begin{array}{llll}\mathrm{SR} & \left([e-m i-k a c h e]_{\mathrm{PP}}\right. & {[\mathrm{e}-\mathrm{my}-\text { aange }]_{\mathrm{PP}}} & \left.[\mathrm{e}-\mathrm{mi}-\mathrm{inji}]_{\mathrm{PP}}\right)_{\mathrm{IP}} \\ \mathrm{UR} & e-m i-k a c h i & \text { e-mi-angu } & \text { e-mi-inji } \\ & \begin{array}{l}\text { AUG-4-maize stalk } \\ \text { 'many light maize stalks' }\end{array} & \text { AUG-4-light } & \text { AUG-4-many }\end{array}$

For vowel assimilation to take place, at a word-word boundary, the following word must have a long vowel in the second syllable. If the following word has a short vowel in the second syllable, assimilation does not take place. Consider the example in (27).

$$
\begin{aligned}
& \text { (27) SR } \quad\left([b-a-b u k u l]_{P P}\right)_{I P} \quad\left([o-m u-k h a a n o]_{P P} \quad[o-m w-a a n g u]_{P P}\right)_{I P .}
\end{aligned}
$$

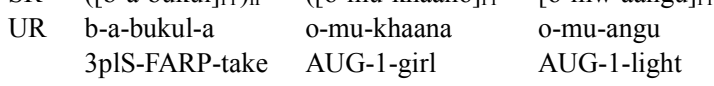

$$
\begin{aligned}
& \text { 'They took a light girl.' }
\end{aligned}
$$

In this example the second phonological phrase has a short vowel in the second syllable, while the third phonological phrase has a long vowel in the second syllable. In this case the final vowel of the second phonological phrase assimilates to the initial vowel of the third phonological phrase. On the other hand, the final vowel of the first phonological phrase

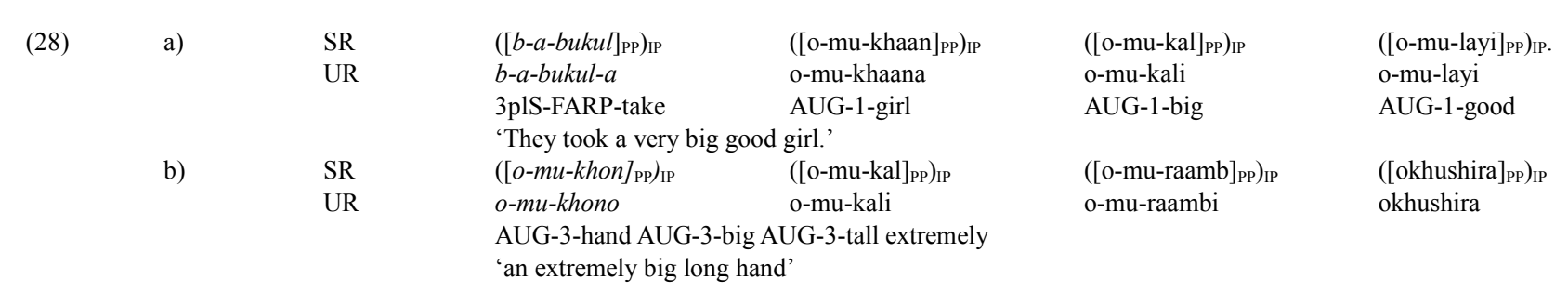

The examples in (28) are made up of two independent syntactic words. Consequently, they are made up of two separate phonological words and hence two separate phonological phrases. We saw in section 3.4 that constructions made up of two or more separate phonological phrases constitute intonational phrases. Further, it was argued that assimilation takes place within an intonational phrase. Nevertheless, assimilation is blocked in the examples in (27) and (28), because separate intonational phrases are involved. Consequently, assimilation does not apply across intonational phrase boundaries. This then justifies further our argument in the preceding section that the domain for assimilation is within an intonational phrase. Since deletion occurs here instead of assimilation, it is argued deletion applies at an intonational phrase boundary and not within an intonational phrase. In accordance, the domain for deletion is at the end of an intonational phrase.

The intonational phrase is characterised as being affected by factors of length [29]. Vowel deletion in Kisa is variable in application. One major factor determining the applicability of does not assimilate to the initial vowel of the second phonological phrase. This vowel is deleted instead. This means that there is a limit to the domain of application of vowel assimilation.

The data in (27) shows that vowel assimilation, at a word-word boundary in Kisa, occurs within an intonational phrase but it does not occur across intonational phrase boundaries. Consequently, the upper limit of application of vowel assimilation in Kisa is within an intonational phrase.

\subsection{The Domain of Deletion}

Deletion, as illustrated in the data in (28) repeated here from section 4.5 occurs at the juncture of two independent words. this rule is the length of the vowel in the second syllable of the following word. This can be observed by looking at the environment in which vowel deletion occurs (section 5.5 and in the data in (27) and (28)) and in which it does not occur (section 4.4 and in the data in (26)). At the juncture of phonological words hence phonological phrases, the final vowel of the first word is deleted when the following word has a short vowel in the second syllable. When the following word has a long vowel in the second syllable, the final vowel of the first word does not delete, instead it assimilates to the initial vowel of the following word. This phenomenon, dependency on length, is a characteristic of the intonational phrase [26, 28-29]. Consequently, the variability found in the application of vowel deletion in Kisa suggests that this rule has the intonational phrase as its domain. This, then, justifies further the argument above that the domain for deletion is at the end of an intonational phrase, while the domain for assimilation is within an intonational phrase. 


\section{Conclusion}

This study looked at the strategies used in resolving unacceptable vowel sequences in Kisa with the sole aim of delimiting the prosodic domains in which they apply. The findings show that unacceptable vowel sequences occur both at morphological and syntactic boundaries in Kisa. The strategies used at each boundary differ depending on the combining vowels. Gliding occurs at morphological boundaries and involve the high vowels $/ \mathrm{i} /$ and $/ \mathrm{u} /$ followed by any other vowel (a, e, o, i, u) except itself. Coalescence occurs at morphological boundaries but involves the low vowel /a/ followed by the high vowels /i/ or /u/. Raising, on the other hand, occurs at a syntactic boundary involving a proclitic and a host and involves the low vowel /a/ followed by the high vowels/i/. Assimilation occurs both at morphological and syntactic boundaries and involves all the five vowels followed by the vowels $(\mathrm{e}, \mathrm{a}, \mathrm{o})$ only. It applies at a syntactic boundary involving two words, only when the second syllable of the second word has a long vowel. Deletion occurs at a syntactic boundary involving two words only when the second word has a short vowel in the second syllable and involves all the five vowels followed the vowels (e, a, o) only. Further, the findings of the study show that these vowel processes apply in different domains. Gliding, coalescence and raising have their domain of application as the phonological word. Assimilation has its upper limit of application as within an intonational phrase, while deletion applies at the end of an intonational phrase.

The discussion in this study shows that vowel height in Kisa is sensitive to word boundaries. The vowel feature [+high] is preserved at the beginning of a word in Kisa. This explains why the high front vowel /i/ does not change when preceded by any of the four vowels /a, e, o, u/ at a proclitic-host and word-word boundary. The high front vowel $/ \mathrm{i} /$, however, changes to the mid front vowel /e/ when preceded by the low vowel /a/ at an affix-root boundary. Note, however, that at an affix-root and a proclitic-host boundary the low vowel /a/ changes to /e/ when followed by /i/ but it does not change at a word-word boundary. This means that vowels of conflicting qualities are not allowed within a phonological word in Kisa. This shows that affixes and stems, as well as proclitics and hosts, form a single phonological word, while two separate phonological words form larger prosodic constituents, thus phonological phrases and intonational phrases. Phonological words include simple, complex and compound words as well as cliticised forms. Phonological phrases, on the other hand, are made up of a single phonological word involving heads and post modifiers.

The vowel processes discussed and the domains in which they apply offer a clue to the mapping of the morphological and syntactic structure into the prosodic structure. They provide evidence from Kisa to the effect that there is a prosodic structure to a sentence that is derived from, yet at the same time distinct from, syntactic structure. Therefore, phonological words, phonological phrases and intonational phrases in Kisa are phonological constituents whose delimitation is based on the morphological word and the syntactic phrase and other morphological, phonological and syntactic considerations in the language.

\section{References}

[1] Nespor, M. \& Vogel, I. (1986). Prosodic Phonology. Dordrecht: D. Reidel.

[2] McCarthy, J. (2011). Pausal Phonology and Morpheme Realization. In T. Borowsky, S. Kawahara, T. Shinya \& M. Sugahara (Eds.), Prosody Matters: Essays in Honor of Lisa Selkirk. London: Equinox. Available at: http://works.bepress.com/john_j_mccarthy/4.

[3] McCarthy, J. \& Prince, A. (1995). Prosodic Morphology. In J. Goldsmith (Ed.) The Handbook of Phonological Theory (pp. 318-366). Cambridge, MA: Blackwell.

[4] Selkirk, E. (1980). Prosodic Domains in Phonology: Sanskrit Revisited. In M. Aronoff \& M-L. Kean (Eds.), Juncture (pp. 107-29). Saratoga, CA: Anma Libri.

[5] Elfner, E. (2018). The syntax-prosody interface: current theoretical approaches and outstanding questions. Linguistics Vanguard, 1-14.

[6] Hamlaoui, F. \& Kriszta S. (2017). The syntax-phonology mapping of intonational phrases in complex sentences: A flexible approach. In L. Clemens \& E. Elfner (eds.), Special collection: Prosody \& constituent structure. Glossa, 2 (1). 55.

[7] Windsor, J. W. (2017). Predicting prosodic structure by morphosyntactic category: A case study of Blackfoot. In L. Clemens \& E. Elfner (eds.), Special collection: Prosody \& constituent structure. Glossa, 2 (1). 10.

[8] Gibbon, D. \& Sascha G. (2017). Multilinear Grammar: Ranks and Interpretations. Open Linguistics, 3 (1).

[9] Niebuhr, O. \& Nigel, G. W, (eds.). (2018). Prosody and Pragmatic Functions. Special issue of JIPA, 48 (1).

[10] Casali, R. F. (1997). Vowel Elision in Hiatus Contexts: Which Vowel Goes? Language, 73 (3), 493-534.

[11] Pulleyblank, D. (2003). Yoruba Vowel Patterns: Asymmetries Through Phonological Competition. Ms, University of British Columbia.

[12] Rosenthall, S. (1994). Vowel/Glide Interaction in a Theory of Constraint Interaction. University of Massachusetts-Amherst Doctoral dissertation.

[13] Sibanda, G. (2009). Vowel Processes in Nguni: Resolving the Problem of Unacceptable VV Sequences. In M. Matondo, F. Mc Laughlin \& E. Potsdam (Eds.), Selected Proceedings of the 38th Annual Conference on African Linguistics: Linguistic Theory and African Language Documentation (pp. 38-55). Somerville: Cascadilla Proceedings Project.

[14] Harford, C. (1997). When Two Vowels Go Walking: Vowel Coalescence in Shona. Zambezia, 24, 69-85.

[15] Mtenje, A. (2007). On Recent Trends in Phonology: Vowel Sequences in Bantu Languages. SOAS Working Papers in Linguistics, 15, 33-48.

[16] Sample, W. A. (1976). The Application of Rules in the Phonology of Olukisa. Indiana University Doctoral Dissertation. 
[17] Tanner, D. S. (2006). Context Insensitive Vowel Hiatus Resolution in Ciyao. University of Washington working papers in Linguistics Online 25.

[18] Pulleyblank, D. (1988). Vocalic Underspecification in Yoruba. Linguistic Inquiry, 19, 233-270.

[19] Akinlabi, A. (1993). Underspecification and the Phonology of Yoruba /r/. Linguistic Inquiry, 24, 139-160.

[20] Pulleyblank, D. (1998). Yoruba Vowel Patterns: Deriving Asymmetries by the Tension Between Opposing Constraints. Paper presented at the South Western Optimality Theory Conference, University of Arizona.

[21] Buchstaller, I., \& Khattab, G. (2003). Population Samples. Data without generalisation is just gossip. Pirsing 1991: 55, in Chambers 2003: xix.

[22] Chomsky, N. (1962). The Logical Basis of Linguistic Theory. International Congress of Linguists. Cambridge, Massachusetts: MIT Press.

[23] Creswell, J. W. (1998). Qualitative Inquiry and Research Design: Choosing Among Five Traditions. London: Sage Publication.

[24] Vaux, B., \& Cooper, J. (2005). Introduction to Linguistic Field Methods. Muenchen: LINCOM GmbH Publisher.
[25] Selkirk, E. (1978). On Prosodic Structure and Its Relation to Syntactic Structure. In T. Fretheim (Ed.), Nordic Prosody (pp. 111-140). Trondheim: TAPIR.

[26] Selkirk, E. (1984). Phonology and Syntax: The Relation between Sound and Structure. Cambridge, MA: MIT Press.

[27] Selkirk, E. (1986). On Derived Domains in Sentence Phonology. Phonology, 3, 371-405.

[28] Nespor, M. \& Vogel, I. (1982). Prosodic Domains of External Sandhi Rules. In H. van der Hulst \& N. Smith (Eds.), The Structure of Phonological Representations (pp. 225-265). Dordrecht: Foris.

[29] Hayes, B. (1984). The Phonology of Rhythm in English. Linguistic Inquiry, 15, 33-74.

[30] Hyman, L. M. \& Katamba, F. (2001). The Word in Luganda. In E. Voeltz (Ed.), Proceedings of Cologne Conference on Typology.

[31] Spencer, A. (1986). Towards a Theory of Phonological Development. Lingua, 68, 3-38.

[32] Spencer, A. (1996). Phonology Theory and Description. Oxford: Blackwell. 